\title{
Effect of Maleic Anhydride-Modified Poly(lactic acid) on the Properties of Its Hybrid Fiber Biocomposites
}

\author{
Abubakar Umar Birnin-Yauri ${ }^{1,2, *}$, Nor Azowa Ibrahim ${ }^{1,3, *}$, Norhazlin Zainuddin ${ }^{1}$, \\ Khalina Abdan 4 , Yoon Yee Then ${ }^{1,5}$ and Buong Woei Chieng 1,3 \\ 1 Department of Chemistry, Faculty of Science, Universiti Putra Malaysia, UPM Serdang, 43400 Selangor, \\ Malaysia; norhazlin@upm.edu.my (N.Z.); ThenYoonYee@imu.edu.my (Y.Y.T.); \\ chieng891@gmail.com (B.W.C.) \\ 2 Department of Pure and Applied Chemistry, Kebbi State University of Science and Technology, P.M.B 1144, \\ Aliero, 863102 Kebbi, Nigeria \\ 3 Materials Processing and Technology Laboratory, Institute of Advanced Technology, Universiti Putra \\ Malaysia, UPM Serdang, 43400 Selangor, Malaysia \\ 4 Department of Biological and Agricultural Engineering, Faculty of Engineering, Universiti Putra Malaysia, \\ UPM Serdang, 43400 Selangor, Malaysia; khalina@upm.edu.my \\ 5 Department of Pharmaceutical Chemistry, School of Pharmacy, International Medical University, No. 126, \\ Jalan Jalil Perkasa 19, Bukit Jalil, 57000 Kuala Lumpur, Malaysia \\ * Correspondence: abubkumar@gmail.com (A.U.B.-Y.); norazowa@upm.edu.my (N.A.I.); \\ Tel.: +603-8946-6602 (A.U.B.-Y.); +601-4633-9891 (N.A.I.)
}

Academic Editor: Helmut Schlaad

Received: 25 March 2017; Accepted: 2 May 2017; Published: 5 May 2017

\begin{abstract}
This work investigated the effect of maleic anhydride (MA)-modified poly(lactic acid) (PLA), which is melt-blended with different untreated and aqueous borax (BR)-treated hybrid oil palm empty fruit bunch fibers (EFBF)/Kenaf core fibers (KCF), and compression-molded into corresponding hybrid biocomposites. These hybrid systems includes BR-treated EFBF/BR-treated KCF reinforced MA-modified PLA i.e., BR(EFBF-KCF)-MAPLA, BR-treated EFBF/BR-treated KCF reinforced unmodified PLA i.e., BR(EFBF-KCF)-PLA, untreated EFBF/untreated KCF reinforced MA-modified PLA i.e., EFBF-KCF-MAPLA, and untreated EFBF/untreated KCF reinforced unmodified PLA i.e., EFBF-KCF-PLA respectively. Characterizations of the hybrid systems revealed that optimal mechanical, physical, morphological, thermal and dynamic mechanical properties were provided by the BR(EFBF-KCF)-MAPLA, resulting from improved interface adhesion, consequent of the synergistic influence of BR treatment of natural fibers, and the compatibilization effect provided by the MA-modified PLA. The grafting degree and efficiency of MA onto the PLA backbone was appreciable, as indicated by direct titration, and through monitoring using Fourier Transform Infrared Spectroscopy (FTIR); thus the MA-modified PLA facilitated the formation of strong interface adhesion with the BR-treated hybrid fibers. The BR(EFBF-KCF)-MAPLA showed promising properties for usage as a bio-inspired, and sustainable alternative fiberboard article.
\end{abstract}

Keywords: poly(lactic acid); maleic anhydride; hybrid biocomposites; bio-inspired

\section{Introduction}

Polymer biocomposites have attracted growing research interest in relation to the utilization of naturally occurring lignocellulosic fibers and bio-based polymer matrices. Natural fiber is a broad term which refers to a wide range of plants, animals and mineral fibers [1]. Wood fibers and agro-based fibers such as bast and stem (e.g., hemp, jute, Kenaf etc.), leaf (e.g., banana, pineapple, sisal etc.), seed (oil palm, cotton etc.) are the commonly known fibers in the natural fiber based polymer composite industries [2]. 
Oil palm tree (Eleis guineesis) is a natural reservoir of biomass resource such as oil palm mesocarp fiber (OPMF), empty fruit bunch fiber (EFBF), oil palm trunk (OPT), oil palm fond (OPF), presses fruit fiber (PFF) etc. The oil palm tree is a major economic crop in southeast Asian countries such as Malaysia and Indonesia. It is also produced in large quantity in India and Latin America. The cultivation of oil palm plantation is commercially in large quantities, making the aforementioned countries the major producers in the world. Other oil palm producing countries include Columbia, Ecuador, Nigeria, Ivory Coast, Papua New Guinea and Thailand.The southeast Asian countries i.e., Malaysia and Indonesia, are the largest producers with ca. $85 \%$ of the world supply [3].

Malaysia is the world leading commercial exporter of palm oil and oil palm products having ca. $65 \%$ global market share. Oil palm plantations in Malaysia cover about six million hectares, and large quantities of biomass are generated approximately 100 million tons [3]. EFBF was reported to be the most abundant ca. 12.4 million tons per year [4]. EFBF is often unsystematically utilized by Malaysian oil palm industries as boiler fuel for energy generation, thereby contributing harmfully to atmospheric pollution. Despite that, an appreciable quantity is often left at the field as waste to decay. Leftover EFBF, upon decaying could contribute greatly to adverse environmental problems. Additionally, the Malaysian medium density fiberboard (MDF) mills use EFBF to supplement or substitute rubberwood as their basic raw material for production. The Agro-bio fiber Sdn Bhd Malaysia has patented EFBF-based MDF for over a decade [5]. The major issue worthy of concern here is sustaining the supply chain for EFBF raw materials, as there could be a likelihood that the demand may outstrip supply in the future, due to unsustainable applications.

However, Malaysia has recently focused on the abundant production of Kenaf plant (Hibiscus cannabinus L.) for fiber production, largely to replace the cultivation and production of tobacco plants by farmers [6]. The Malaysian government has invested ca. RM 12 million on Kenaf research and subsequent development of the Kenaf based industry, through the National Kenaf Research and Development Program under the Ninth Malaysia Plan [7].

Kenaf was transported to Asia via the Mesopotamia territory by sea and caravan. India is the leading producer of the Kenaf plant. Other nations involved in the commercial production of Kenaf include Pakistan, China, Cambodia, Brazil, Cuba, Vietnam, Thailand, Indonesia and many countries in the African continents. Kenaf is rich in both bast and core fibers [8,9]. The Kenaf core fiber (KCF) is light-weighted and rich in lignin, though its high content of hemicellulose and low content of cellulose are its major drawbacks for biocomposite fabrication [10]. Therefore, hybridization of the EFBF and KCF may provide synergism in the material properties, due to possible compatibility between the two natural fibers. Also, hybridization could enable the sustainability of EFBF, considering the growth variation between the two fiber sources. The oil palm tree can take up to 2.5-4 years to grow [11,12], while Kenaf plants take only 150-60 days to attain maturity [13].

Previously, a positive hybrid effect in terms of the mechanical and physical properties of KCF incorporated-EFBF reinforced PLA biocomposites was reported by our research group [14]. The hybrid biocomposites developed in our previous work were intended to be used as an alternative to MDF, which popularly uses carcinogenic urea formaldehyde (UF) [15-17]. As a greener option, our previous work employed PLA as polymer matrix, owing to its attractive mechanical and environmental properties. PLA was previously reported to possess high strength, modulus and biocompatibility [18]. The hybrid biocomposites recorded higher density than the conventional MDF, which was resulted from high contents of hemicellulose and impurities in the EFBF and KCF used, as well as the brittle nature of the PLA. A major challenge associated with fabrication and utilization of the natural fiber reinforced biocomposite is the poor adhesion between the hydrophilic fiber and hydrophobic polymer $[19,20]$. This problem can be ascribed to the hydrophilic nature of the natural fibers and hydrophobicity of the polymer matrix [21]. Thus, the natural fibers need to be modified to produce an improved surface for bonding with the polymer matrices.

Several works were reported for the modification of natural fibers, involving physical, chemical and biological methods [22-24]. However, these reported methods suffered from some limitations 
regarding environmental and economic issues. Recently, borax (BR) was employed as a green chemical treatment technique, either as a filler or in its impregnated state [25-27]. Yet, BR in the aforesaid states, can unfavorably affect the material properties of biocomposites, perhaps, due to excess or unreacted $\mathrm{BR}$ in the biocomposites, which has hygroscopic properties [27]. Thus, an alternative method involving $\mathrm{BR}$ impregnation of EFBF and KCF, with a water-washing procedure was reported by us [28].

The BR-treated EFBF and KCF reported in our earlier work, significantly increased in cellulose and decreased in hemicellulose, with a partial reduction in lignin. Enhancements in the properties of the hybrid biocomposites was observed due to the BR treatment of the natural fibers. Yet, some anomalies were observed in the statistical differences among the tensile and flexural properties of the hybrid biocomposites, as well as some morphological defects, which were attributed to the brittle behavior of PLA, because the polymer was used in an unmodified state.

Unlike our preceding works, the novel approach in the present study intended to hybridize BR-treated EFBF as a primary fiber ( $55 \mathrm{wt} \%$ ), and BR-treated KCF as a secondary fiber ( $5 \mathrm{wt} \%$ ), and use these as reinforcements in maleic anhydride (MA)-modified PLA to form a BR(EFBF-KCF)-MAPLA hybrid system. Evaluation of the material performance of the BR(EFBF-KCF)-MAPLA hybrid system would be investigated and compared to those of its corresponding hybrid systems, such as BR-treated EFBF/BR-treated KCF reinforced unmodified PLA (i.e., BR(EFBF-KCF)-PLA), untreated EFBF/untreated KCF reinforced MA-modified PLA (i.e., EFBF-KCF-MAPLA), and untreated EFBF/ untreated KCF reinforced unmodified PLA (i.e., EFBF-KCF-PLA). The integrated approaches of BR treatment of fibers, and compatibilization with MA-modified PLA were an attempt to follow the tricorner fabrication of hybrid biocomposites as previously posited by [29]. The tricorner design of hybrid fiber polymer biocomposites involved a chemical modification of the fiber reinforcements, as well as the polymer matrix, in order to achieve a relatively high performance in the synergistic properties of the hybrid biocomposites.

To the best of our knowledge, this present work reports the first attempt to use MA-modified PLA for the compatibilization of BR-treated hybrid EFBF-KCF at a ratio of 55:5 weight percent loadings of the hybrid fiber reinforcements, aiming at synergistically improved material properties (i.e., mechanical, physical, morphological, thermal and dynamic mechanical) of the hybrid biocomposites.

\section{Materials and Methods}

\subsection{Materials}

Poly(lactic acid) was purchased from NatureWorks LLC (Minnetonka, MN, USA) under the trade name, polylactide resin 3052D. It has a melting point range between 170 and $190{ }^{\circ} \mathrm{C}$, a density ranging from 1.4 to $1.5 \mathrm{~g} \cdot \mathrm{cm}^{-3}$, and a molecular weight of $93,500 \mathrm{~g} / \mathrm{mol}$. Oil palm fiber, i.e., EFBF was obtained from Sabutek (M) Sdn. Bhd. (Kuala Lumpur, Malaysia). Kenaf core fiber, i.e., KCF was supplied by the Lembaga Kenaf dan Tembakau (Kelantan, Malaysia). Sodium tetraborate decahydrate (borax), maleic anhydride and all other chemicals were purchased from R \& M Chemicals (Selangor, Malaysia).

\subsection{Methods}

\subsubsection{Fiber Purification}

EFBF and KCF were purified by physical sorting, and then soaked in distilled water for $24 \mathrm{~h}$ at $25^{\circ} \mathrm{C}$, washed with warm water heated at $60{ }^{\circ} \mathrm{C}$, cleaned with acetone (analytical grade, $99.5 \%$ purity), and placed in an oven to dry at $60{ }^{\circ} \mathrm{C}$ overnight. The oven-dried fibers were then ground using a commercial grinder (Waring products division, Torrington, $\mathrm{CT}, \mathrm{USA}$ ), sieved into sizes ranging from $300-400 \mu \mathrm{m}$, and then stored in sealed plastic bags at $25^{\circ} \mathrm{C}$ for subsequent investigations. 


\subsubsection{BR Treatment of Natural Fibers}

Oven-dried, purified EFBF and KCF were chemically treated by soaking in an aqueous BR solution (5 wt \% concentration), in accordance with our previous method [28]. The $\mathrm{pH}$ of the solution was measured to be alkaline at $\mathrm{pH}$ 9.1. The experimental temperature and time were $25^{\circ} \mathrm{C}$ and $24 \mathrm{~h}$, respectively. Afterward, the BR impregnated natural fibers were carefully washed with distilled water, with intermittent $\mathrm{pH}$ monitoring until a neutral $\mathrm{pH}$ was attained. Subsequently, the BR-treated natural fibers were oven-dried at $60^{\circ} \mathrm{C}$ for $24 \mathrm{~h}$. The oven-dried treated natural fibers were then kept in sealed plastic containers at room temperature for subsequent investigations.

\subsubsection{PLA Modification}

The grafting of MA onto PLA was conducted via melt-blending in a Brabender Internal Mixer (Duisburg, Germany) at $170{ }^{\circ} \mathrm{C}$, with a $50 \mathrm{rpm}$ rotor speed for $15 \mathrm{~min}$, in accordance with the method reported by [30], with some modifications. Initially, the PLA was oven-dried at $60^{\circ} \mathrm{C}$ overnight in order to prevent its degradation due to hydrolysis during hot blending as previously posited by [18]. Oven-dried neat PLA (36.35 wt \%), was melted in the Brabender for $5 \mathrm{~min}$, benzoylperoxide (BPO) $(0.75 \mathrm{wt} \%)$ was added and mixed for additional $2 \mathrm{~min}$, and finally MA $(3.00 \mathrm{wt} \%)$ was added and mixed continuously for $8 \mathrm{~min}$. The blend was placed in a vacuum oven at $80^{\circ} \mathrm{C}$ overnight to eliminate unreacted MA and BPO.

Purification was done by dissolving weighted MA grafted-PLA (2.00 g) in $40 \mathrm{~mL}$ chloroform, followed by addition of $0.75 \mathrm{~mL}$ of $1 \mathrm{M} \mathrm{HCl}$ in order to hydrolyze the anhydride into carboxylic acid at room temperature, in accordance with the reported method by [30]. Thereafter, the sample was precipitated by drop-wise addition into $400 \mathrm{~mL}$ acetone to remove the homo- copolymer of MA. The filtered precipitate was washed with acetone and distilled water several times, and vacuum oven-dried at $80^{\circ} \mathrm{C}$ overnight. Thereafter, direct titration was employed to determine the degree of grafting. Purified PLA (0.4 g) was dissolved in $20 \mathrm{~mL}$ chloroform. The solution was titrated against sodium hydroxide $(\mathrm{NaOH})$ in methanol $(0.04 \mathrm{M})$ using a phenolphthalein indicator. The grafting degree was finally calculated using the volume and normality of $\mathrm{NaOH}$ (i.e., $N_{\mathrm{NaOH}}$ and $V_{\mathrm{NaOH}}$ ), as well as the sample weight ( $\left.m_{\text {sample }}\right)$ as shown in Equation (1).

$$
\text { MA grafting }(\%)=\frac{N_{\mathrm{NaOH}} V_{\mathrm{NaOH}}}{2000 \times m_{\text {sample }}} \times 98.06 \times 100
$$

Fourier transform infrared spectroscopy (FTIR) was employed to monitor the grafting process of MA onto the PLA backbone. The experiment was conducted using a Perkin Elmer Spectrum 100 series spectrophotometer (Waltham, MA, USA), which was equipped with an attenuated total reflectance (ATR) capacity. FTIR spectra were recorded at a wave number range of $400-4000 \mathrm{~cm}^{-1}$. The MA-modified PLA was examined, and comparison was made with neat PLA and pure MA respectively.

\subsubsection{Fabrication of Hybrid Fiber-PLA Biocomposites}

To prepare the hybrid biocomposites, oven-dried BR-treated KCF (BRKCF) (5 wt \%), as a secondary fiber, was mixed manually with BR-treated EFBF (BREFBF) (55 wt \%), melt-blended with $40 \mathrm{wt} \%$ MA-modified PLA (MAPLA), and compression-molded into sheets with dimensions of $1 \mathrm{~mm} \times 150 \mathrm{~mm} \times 150 \mathrm{~mm}$, and $3 \mathrm{~mm} \times 150 \mathrm{~mm} \times 150 \mathrm{~mm}$ (thickness $\times$ length $\times$ width). Compression molding was performed using a hydraulic hot press at $170^{\circ} \mathrm{C}, 150 \mathrm{~kg} \cdot \mathrm{cm}^{-12}$, and $10 \mathrm{~min}$ molding temperature, pressure, and time, respectively. Cooling was then performed at $30^{\circ} \mathrm{C}$ for $5 \mathrm{~min}$.

Corresponding hybrid biocomposites, using the same sample formulations as above, were similarly fabricated by melt-blending and compression-molding, these included untreated hybrid fiber (EFBF-KCF) reinforced unmodified PLA, untreated hybrid fiber (EFBF-KCF) reinforced MA-modified 
PLA, and BR-treated hybrid fiber (EFBF-KCF) reinforced unmodified PLA, respectively. The various sample formulations of the hybrid biocomposites are depicted in Table 1.

Table 1. Hybrid fiber-poly(lactic acid) (PLA) mixing formulations.

\begin{tabular}{ccccccc}
\hline Sample Code & EFBF (wt \%) & KCF (wt \%) & PLA (wt \%) & BR Modifier & MA (wt \%) & BPO (wt \%) \\
\hline EFBF-KCF-PLA & 55 & 5 & 40 & - & - & - \\
EFBF-KCF-MAPLA & 55 & 5 & 36.25 & - & 3 & 0.75 \\
BR(EFBF-KCF)-PLA & 55 & 5 & 40 & yes & - & - \\
BR(EFBF-KCF)-MAPLA & 55 & 5 & 36.25 & yes & 3 & 0.75 \\
\hline EFBF: Empty fruit bunch fibers, KCF: Kenaf core fibers, MA: maleic anhydride, MAPLA: MA-modified PLA, \\
BR: Borax-treated.
\end{tabular}

\section{Characterizations}

\subsection{Mechanical Properties}

The tensile properties of the hybrid biocomposites were tested using a universal testing machine (Model 3365, Instron Corp., Norwood, MA, USA), equipped with a 5-kN load cell, $5 \mathrm{~mm} / \mathrm{min}$ crosshead speed, and $25^{\circ} \mathrm{C}$ experiment temperature. Five dog-bone shaped specimens were tested as specified by the ASTM D638-5 (2000) testing standard. Average values and standard deviation were reported for the tensile strength (TS), tensile modulus (TM), and elongation at break (EB) tests.

The flexural properties (three-point testing) of the hybrid biocomposites were performed using a universal testing machine (Model 3365, Instron Corp., Norwood, MA, USA), equipped with a 5-kN load cell, $1.3 \mathrm{~mm} / \mathrm{min}$ crosshead speed, and $48 \mathrm{~mm}$ span length. The test was performed at $25^{\circ} \mathrm{C}$ on five specimens with the dimensions $127.0 \mathrm{~mm} \times 12.7 \mathrm{~mm} \times 3.0 \mathrm{~mm}$, in accordance with the ASTM D790 (2000) testing standard. Average values and standard deviation were reported for the flexural strength (FS) and flexural modulus (FM) tests.

The impact strength (IS) of the hybrid biocomposites was examined following the un-notched IZOD impact test, as specified by the ASTM D256 (2000) testing standard. The impact tester (Izod, Computerized, International Equipments, Mumbai, India) was equipped with a 7.5-J pendulum. The test was performed at $25^{\circ} \mathrm{C}$ on five specimens with the dimensions, $63.5 \mathrm{~mm} \times 12.7 \mathrm{~mm} \times 3.0 \mathrm{~mm}$, and the average values and standard deviations were reported.

\subsection{Physical Properties}

To test for the dimensional stability (i.e., water uptake and thickness swelling) of the hybrid biocomposites, test samples with the dimensions, $10.0 \mathrm{~mm} \times 10.0 \mathrm{~mm} \times 1.0 \mathrm{~mm}$, were cut according to the ASTM D570 (2005) and EN 317 (1993) testing standards, respectively. The initial weight $\left(W_{1}\right)$ and thickness $\left(T_{1}\right)$ of the oven-dried test samples were measured and recorded. Test samples were then soaked in distilled water for $24 \mathrm{~h}$ at $25^{\circ} \mathrm{C}$. Thereafter, the samples were towel dried using tissue and measured for their second weight $\left(W_{2}\right)$ and thickness $\left(T_{2}\right)$. Five specimens for each sample were tested to determine the mean and standard deviation. The water uptake and thickness swelling were calculated using the following Equations (2) and (3) respectively:

$$
\begin{gathered}
\text { Water Uptake }(\%)=\frac{W_{2}-W_{1}}{W_{1}} \times 100 \\
\text { Thickness Swelling }(\%)=\frac{T_{2}-T_{1}}{T_{1}} \times 100
\end{gathered}
$$

Moreover, the densities of the hybrid biocomposites were measured in accordance with the BS EN 323 (1993) testing standard, as reported by the European Committee for Standardization [9]. The mass of the test samples having standard dimensions i.e., $1 \mathrm{~mm} \times 150 \mathrm{~mm} \times 150 \mathrm{~mm}$, were obtained using an analytical balance. Afterwards, the volume of the test samples was determined 
using their dimensions, i.e., multiplying their length, width, and thickness, respectively. The density was subsequently calculated using Equation (4). Five tests were conducted, and average values and standard deviations were reported.

$$
\text { Density }=\text { Mass } / \text { Volume }
$$

\subsection{Thermogravimetric Analysis}

Thermogravimetric analysis (TGA) was employed to investigate the thermal stability of the hybrid biocomposites using the Perkin Elmer TGA7 Thermogravimetric analyzer (Waltham, MA, USA). Approximately $10 \mathrm{mg}$ of each test samples were analyzed at $10{ }^{\circ} \mathrm{C} / \mathrm{min}$ heating rate and 25 to $700{ }^{\circ} \mathrm{C}$ heating range, under a nitrogen atmosphere of $20 \mathrm{~mL} / \mathrm{min}$ nitrogen flow rate. The sample weight losses were noted and plotted against the heating temperatures.

\subsection{Dynamic Mechanical Analysis}

The stiffness and damping (i.e., modulus and tan delta) of the hybrid biocomposites were measured using the Dynamic Mechanical Analyzer (DMAQ800, TA instruments, Newcastle, DE, USA) by means of bending mode according to ASTM D5023-01, as previously reported by [31]. The test samples, having a dimension of $63.5 \mathrm{~mm} \times 12.7 \mathrm{~mm} \times 3.0 \mathrm{~mm}$ (length $\times$ width $\times$ thickness) were analyzed at a temperature scan range of 25 to $170{ }^{\circ} \mathrm{C}$, heating rate of $2{ }^{\circ} \mathrm{C} / \mathrm{min}$ and $1 \mathrm{~Hz}$ frequency of dynamic force under nitrogen atmosphere. The stiffness or modulus i.e., storage modulus $\left(\mathrm{E}^{\prime}\right)$ and loss modulus $\left(\mathrm{E}^{\prime \prime}\right)$, as well as damping or tan delta i.e., loss factor $(\tan \delta)$ of each sample were recorded and plotted as function of temperature.

\subsection{Morphological Analysis of Fractured Surfaces}

Scanning electron microscopy (SEM) was employed to analyze the morphologies of the fractured surfaces of the hybrid biocomposites. The experiment was conducted using a LEO 1455 VP scanning electron microscope (Zeiss, Jena, Germany) operated at a $10 \mathrm{kV}$ accelerating voltage. The oven-dried samples were held in place using a metal holder of the instrument. Afterward, conductivity of the samples was enhanced by gold coating for 3 min using a Bio-Rad ${ }^{\mathrm{TM}}$ coating system (Hercules, CA, USA) before the commencement of the experiment.

\section{Results and Discussion}

The influence of MA-modified PLA on the mechanical, physical, thermal, dynamic mechanical and morphological properties of its hybrid biocomposites reinforced with BR-treated EFBF/KCF were investigated, and the test results are presented and discussed in the succeeding subsections.

\subsection{Grafting Degree, Efficiency and FTIR Spectra of MA-Modified PLA}

There are three major steps involved in the mechanism for the MA grafting of PLA, and its subsequent compatibilization to natural fibers (Figure 1). Firstly, the PLA reacts with BPO (initiator), where deprotonation occur and PLA macroradicals (PLA*) are generated. Secondly, the MA reacts with the PLA macroradicals to form MA-grafted PLA, which lastly, form bonds with the natural fibers, and provides compatibilization effects.

The degree and efficiency of MA grafting onto the PLA backbone was probed by direct titrimetric method, and calculated to be $0.87 \%$ and $16.58 \%$, respectively. Both the grafting degree and efficiency was low, which may be have been a result of PLA degradation that occurred, consequent of thermal decomposition of $\mathrm{BPO}$ and MA on the PLA backbone during melt-blending. 


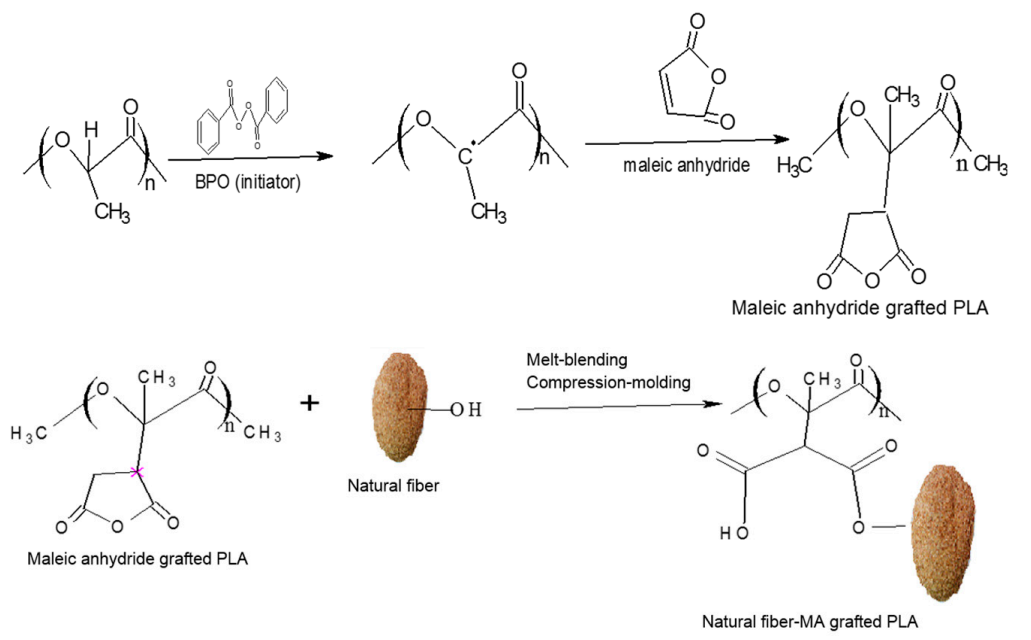

Figure 1. Hypothetical mechanism for MA grafting of PLA, and compatibilization with fibers.

Several works previously reported that extrusion and reactive melt-blending often cause low grafting efficiency [32,33]. Nonetheless, the degree of grafting observed, appeared to be slightly higher than the one previously reported by [34], where the authors used relatively higher molecular weight $\left(M_{\mathrm{W}}\right)$ PLA. In this study, the low degree of MA grafting onto PLA could be associated with the low $M_{\mathrm{W}}$ of the PLA used. The $M_{\mathrm{W}}$ of PLA is $93,500 \mathrm{~g} / \mathrm{mol}$, which is previously reported to be a low $M_{\mathrm{W}}$ PLA by [35]. Low $M_{\mathrm{w}}$ PLA often provides a higher grafting percentage than the high $M_{\mathrm{W}}$ PLA. The PLA molecules suffers entanglement during the MA grafting reaction of high $M_{\mathrm{W}}$ PLA, thereby restricting efficient diffusion of reacting molecules onto the PLA backbone, hence, hampering the grafting efficiency. On the other hand, the results for the MA grafting onto PLA appeared to be lower than the observation reported by [32], where the authors enhanced MA grafting onto PLA using a styrene comonomer.

The grafting reaction of MA onto PLA backbone was monitored by FTIR analysis. FTIR was performed on MA-grafted PLA samples which were previously purified by eliminating residual (unreacted) MA. The FTIR spectra are depicted in Figure 2. The absorption band at $3593 \mathrm{~cm}^{-1}$ in the spectra of pure MA can be assigned to the symmetric $\mathrm{OH}$ stretching vibration of water partially hydrogen-bonded with the hydrophilic carbonyl group of MA [36]. A similar peak appeared at $3592 \mathrm{~cm}^{-1}$ in the spectra of MA-PLA, but did not appear in the neat PLA spectra. The $=\mathrm{C}-\mathrm{H}$ stretching vibration band of anhydride was located at $3126 \mathrm{~cm}^{-1}$ in pure MA, and at $3125-3057 \mathrm{~cm}^{-1}$ in MA-PLA, but disappeared in the neat PLA. This implies that the MA was grafted onto the PLA.

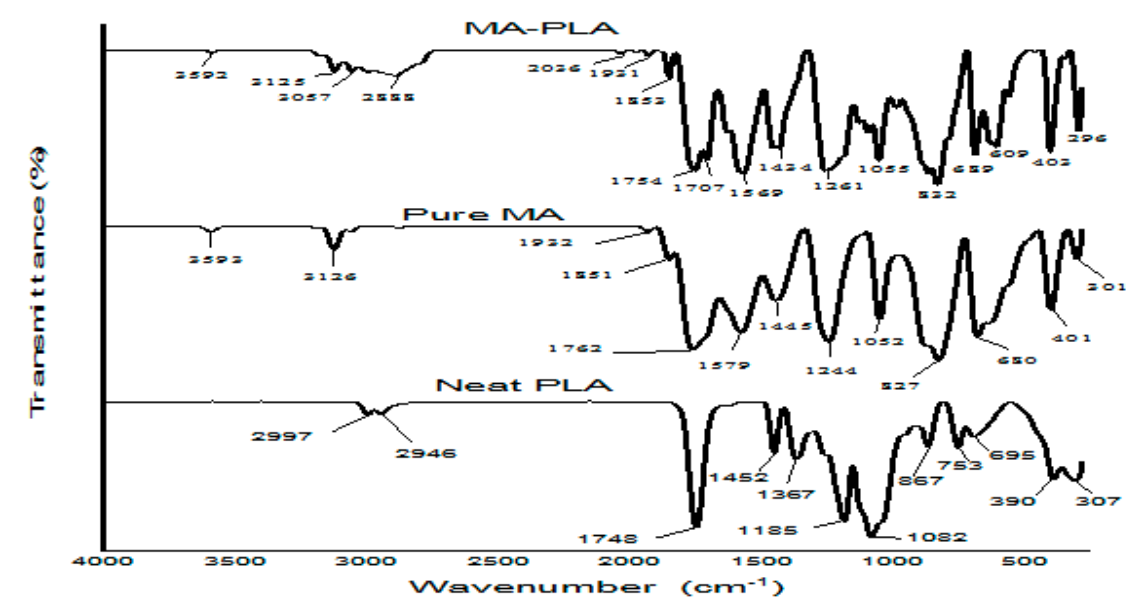

Figure 2. FTIR spectra of neat PLA, Pure MA and MAPLA. 
The absorption band at $2997 \mathrm{~cm}^{-1}$ in neat PLA, was assigned to the C-H stretching of the methyl groups of PLA, this band decreased to $2888 \mathrm{~cm}^{-1}$ in the MAPLA spectra, and did not appear in the pure MA spectrum. The peak at $1748 \mathrm{~cm}^{-1}$ in neat PLA, corresponded to $-\mathrm{C}=\mathrm{O}$ stretching of the carbonyl group in PLA, which increased to $1754 \mathrm{~cm}^{-1}$ in the spectra of MAPLA, perhaps due to grafting reaction. The presence of MA in the FTIR spectra of MA-grafted PLA was previously described by the qualitative appearance of two typical $-\mathrm{C}=\mathrm{O}$ stretching modes at 1756 and $1850 \mathrm{~cm}^{-1}$ for intense symmetric and weak asymmetric vibrations, respectively [37,38]. In the present work, these peaks appeared at 1754 and $1853 \mathrm{~cm}^{-1}$, perhaps, due to the strong intensity of the neighboring $-\mathrm{C}=\mathrm{O}$ stretching of PLA. This observation confirmed the low grafting performance of the melt-blending technique as previously posited by [33].

The peaks at 1452 and $1367 \mathrm{~cm}^{-1}$ in PLA, were ascribed to the $-\mathrm{C}-\mathrm{H}$ deformation and $\mathrm{C}-\mathrm{O}-\mathrm{H}$ absorption bands, respectively. These peaks reduced to 1434 and $1261 \mathrm{~cm}^{-1}$ in MAPLA, perhaps due to the grafting reaction. The reduction of $1185 \mathrm{~cm}^{-1}$ of PLA to $1055 \mathrm{~cm}^{-1}$ in MAPLA, indicated -C-Ostretching of the anhydride group from MA [39]. The absorption peaks at $867 \mathrm{~cm}^{-1}$ in PLA decreased to $832 \mathrm{~cm}^{-1}$ in MAPLA. These peaks were associated with $=\mathrm{C}-\mathrm{O}-\mathrm{C}=$ asymmetric ring-stretching vibration of the saturated cyclic five-membered anhydride compound, as previously observed by [40]. Lastly, the bands at $753 \mathrm{~cm}^{-1}$ in PLA declined to $689 \mathrm{~cm}^{-1}$ in MAPLA, and were assigned as C-H bending vibrations of the anhydride ring involved in the grafting reaction. Generally, the FTIR spectra indicated that the grafting reaction between the PLA and MA successfully occurred.

\subsection{Mechanical Properties}

The mechanical properties i.e., TS, EB, TM, FS, FM, and IS of all the hybrid biocomposites are given in Table 2. The TS of EFBF-KCF-PLA hybrid system recorded $35.59 \mathrm{MPa}$, but declined in EFBF-KCF-MAPLA by about $15.10 \%$. Approximately $5.19 \%$ of increase was recorded by BR(EFBF-KCF)-PLA compared to EFBF-KCF-PLA. These disparities in TS may be attributed to poor fiber-to-PLA interface bonding, arising due to the hydrophilic nature of the fibers and the hydrophobicity of the polymer matrix [41].

Table 2. Mechanical properties of hybrid biocomposites.

\begin{tabular}{ccccccc}
\hline Sample & TS (MPa) & EB (\%) & TM (MPa) & FS (MPa) & FM (GPa) & IS (J/m) \\
\hline EFBF-KCF-PLA & $35.59 \pm 1.32$ & $8.59 \pm 0.84$ & $469.39 \pm 24.11$ & $25.08 \pm 1.80$ & $4.19 \pm 0.20$ & $12.29 \pm 0.50$ \\
EFBF-KCF-MAPLA & $30.92 \pm 2.82$ & $12.62 \pm 1.29$ & $248.64 \pm 39.05$ & $47.33 \pm 3.34$ & $4.65 \pm 0.43$ & $16.12 \pm 0.49$ \\
BR(EFBF-KCF)-PLA & $37.44 \pm 2.56$ & $12.23 \pm 0.45$ & $305.92 \pm 20.64$ & $40.26 \pm 1.19$ & $5.23 \pm 0.15$ & $16.75 \pm 0.49$ \\
BR(EFBF-KCF)-MAPLA & $47.54 \pm 14.50$ & $16.61 \pm 4.09$ & $373.94 \pm 14.29$ & $54.96 \pm 6.53$ & $2.49 \pm 0.10$ & $32.53 \pm 2.18$ \\
\hline
\end{tabular}

TS: Tensile strength, EB: Elongation at break, TM: Tensile modulus, FS: Flexural strength, FM: Flexural modulus, IS:

Impact strength. \pm refers to standard deviation.

The inclusion of untreated hybrid fibers into MA-modified PLA (i.e., EFBF-KCF-MAPLA), provided a TS slightly lower to those involving BR-treated hybrid fibers reinforced unmodified PLA (i.e., BR(EFBF-KCF)-PLA), having an insignificant difference. Upon combining the two methods via the tricorner approach i.e., BR(EFBF-KCF)-MAPLA, a synergistically improved TS was obtained, presenting an approximately $33.36 \%, 53.75 \%$ and $26.98 \%$ increase in TS, compared to the EFBF-KCF-PLA, EFBF-KCF-MAPLA, and BR(EFBF-KCF)-PLA hybrid systems respectively. This could be due to BR elimination of hemicellulose and impurities, and increased cellulose content which enabled the fibers to form strong interface adhesions with the MA-modified PLA, through reactive compatibilization.

The EB of the EFBF-KCF-PLA hybrid system recorded approximately $93.36 \%$ lower compared to the BR(EFBF-KCF)-MAPLA. EFBF-KCF-MAPLA and BR(EFBF-KCF)-PLA hybrid systems presented almost similar EBs, which were higher than EFBF-KCF-PLA, but lower than BR(EFBF-KCF)-MAPLA hybrid systems. This implies that inclusion of the BR-treated hybrid fibers into the MA-modified PLA provided the best $\mathrm{EB}$, which could be due to synergistically improved interface bonds. 
The TM of the BR(EFBF-KCF)-MAPLA showed a slight reduction compared to the EFBF-KCF-PLA, perhaps due to the higher fiber-fiber interaction occurring due to the weakened interface bond in the EFBF-KCF-PLA hybrid system, thereby making the high modulus of the natural fibers dominant in the hybrid biocomposite. The reduced fiber-fiber interactions consequent of the strengthened interface bond, and molecular rearrangements caused by the MA in the BR(EFBF-KCF)-MAPLA tended to slightly decrease the TM. A similar trend can be seen between the EFBF-KCF-MAPLA and BR(EFBF-KCF)-PLA hybrid systems.

The EFBF-KCF-PLA hybrid system presented a FS of $25.08 \mathrm{MPa}$, which recorded a percentage increase of approximately $88.72 \%, 60.53 \%$, and $119.14 \%$ for EFBF-KCF-MAPLA, BR(EFBF-KCF)-PLA, and BR(EFBF-KCF)-MAPLA respectively. Clearly, the BR(EFBF-KCF)-MAPLA hybrid systems recorded the highest increase in FS, which can be imputed to the synergistically improved interface bond, resulted due to BR treatment of fibers and MA modification of PLA.

The BR(EFBF-KCF)-PLA hybrid system recorded the highest FM, while BR(EFBF-KCF)-MAPLA presented the lowest. The EFBF-KCF-PLA and EFBF-KCF-MAPLA hybrid systems presented almost similar FMs. These disparities observed in the FM of the hybrid systems may be associated with the short lengths of the natural fibers used, which also tended to unevenly be distributed or dispersed in the hybrid biocomposites.

The IS of the EFBF-KCF-PLA recorded $12.29 \mathrm{~J} / \mathrm{m}$, which was a percentage increase of approximately $31.16 \%, 36.29 \%$, and $164.69 \%$ for EFBF-KCF-MAPLA, BR(EFBF-KCF)-PLA, and $\mathrm{BR}(\mathrm{EFBF}-\mathrm{KCF})-\mathrm{MAPLA}$ respectively. Clearly, BR(EFBF-KCF)-MAPLA presented the highest increase, which implies that the combined methods of BR treatment of fibers and MA modification of PLA produces stronger hybrid biocomposites, which can absorb high impact energy without crack generation.

Generally, the best mechanical properties were provided by the BR-treated hybrid fiber reinforced MA-modified PLA i.e., BR(EFBF-KCF)-MAPLA hybrid system, which is an indication of synergistically improved interface bonds provided by the BR-treated natural fibers and MA-modified PLA.

\subsection{Physical Properties}

The physical properties i.e., dimensional stability, which includes water uptake (WU) and thickness swelling (TSW), as well as the density of all the hybrid biocomposites were examined and the test results are presented in Table 3.

Table 3. Physical properties of hybrid biocomposites.

\begin{tabular}{cccc}
\hline Sample & WU (\%) & TSW (\%) & Density $\mathbf{( k g \cdot \mathbf { m } ^ { - 3 } \text { ) }}$ \\
\hline EFBF-KCF-PLA & $8.50 \pm 0.54$ & $4.15 \pm 0.75$ & $1066 \pm 16.85$ \\
EFBF-KCF-MAPLA & $10.17 \pm 0.58$ & $5.47 \pm 0.61$ & $1072 \pm 16.33$ \\
BR(EFBF-KCF)-PLA & $6.30 \pm 0.69$ & $3.12 \pm 0.30$ & $992 \pm 27.90$ \\
BR(EFBF-KCF)-MAPLA & $4.25 \pm 0.35$ & $2.50 \pm 0.25$ & $932 \pm 26.12$ \\
\hline
\end{tabular}

WU: Water uptake, TSW: Thickness swelling. \pm refers to standard deviation.

It was seen that the smallest WU, TSW, and density was present in BR(EFBF-KCF)-MAPLA. This may have been due to BR elimination of hydrophilic hemicellulose and impurities from the fibers, coupled with MA modification of PLA, which strengthened the interface bond, thereby making the hybrid system impassable by moisture, as well as other foreign bodies. The presence of these hemicelluloses and impurities in the EFBF-KCF-PLA and EFBF-KCF-MAPLA, may have contributed to their relatively higher WU, TSW, and density.

Similarly, the lowest density provided by the BR(EFBF-KCF)-MAPLA hybrid system (Table 3), could be explained based by its better interface adhesion, with the product consequently possessing no voids, gaps, or micro-cracks. When such defects are present in the hybrid biocomposites, they may serve as penetration points for foreign agents such as water and air, into the hybrid 
biocomposite, thereby adding to its density. The presence of these voids, gaps and micro-cracks in the EFBF-KCF-PLA, EFBF-KCF-MAPLA, and BR(EFBF-KCF)-PLA hybrid systems, as would be visible in their morphologies, and may have contributed to their somewhat higher densities.

The lowering of density was an improvement achieved due to MA modification of PLA, as earlier asserted. Yet, the density for the BR(EFBF-KCF)-MAPLA hybrid system is similar to high density fiberboard (HDF), because it is higher than the density range of $495-801 \mathrm{~kg} \cdot \mathrm{m}^{-3}$ previously reported for conventional MDF, by [42].

Generally, a good correlation was established between the mechanical and physical properties of the hybrid biocomposites; in both, the best results were presented by the BR(EFBF-KCF)-MAPLA hybrid system, consequent of the synergistic improvement of the interface bond, obtained as a result of the combined approaches of BR treatment of natural fibers and MA modification of PLA.

\subsection{Statistical Analysis}

One-way analysis of variance (ANOVA) was used to test the significant difference regarding the mechanical properties (Table 4) and physical properties (Table 5) of the hybrid biocomposites.

The variance of the mechanical properties (i.e., TS, EB, TM, FS, FM, and IS) and physical properties (i.e., WU, TSW and Density) of the samples was decomposed into two components by ANOVA analysis viz., the sum of square between group (SSBG) and the sum of square within group (SSWG). The F-ratio was calculated as a ratio of the SSBG estimate to the SSWG estimate.

It can clearly be seen from Tables 4 and 5 that the $p$ value of the $F$-test for both mechanical and physical properties was less than 0.05 , which indicates that there was a statistically significant difference between the mean mechanical and physical properties from untreated hybrid fiber-unmodified PLA, untreated hybrid fiber-MA modified PLA, BR-treated hybrid fiber-unmodified PLA to their corresponding BR-treated hybrid fiber-MA modified PLA at 95.0\% confidence level.

Table 4. ANOVA Test for mechanical properties of hybrid biocomposites.

\begin{tabular}{ccccccc}
\hline Source & TS & EB & TM & FS & FM & IS \\
\hline TSS & 1599.419042 & 210.7796105 & 307481.1619 & 3057.850788 & 28.69395115 & 1225.5417 \\
SSWG & 961.7113 & 67.058795 & 172898.8654 & 953.845995 & 9.1344369272 & 21.99148 \\
SSBG & 637.7077421 & 143.7208155 & 134582.2965 & 2104.004793 & 19.55951422 & 1203.55022 \\
DFBG & 3 & 3 & 3 & 3 & 3 & 3 \\
DFWG & 16 & 16 & 16 & 16 & 16 & 16 \\
F-ratio & 3.53651658 & 5.333333333 & 4.151399412 & 11.76432984 & 11.42023422 & 291.882787 \\
$p$-value & 0.038846 & 0.009711 & 0.023566 & 0.000254 & 0.000298 & 0.00001 \\
\hline
\end{tabular}

ANOVA: analysis of variance; TS: tensile strength; EB: elongation at break; TM: tensile modulus; FS: flexural strength; FM: flexural modulus; IS: impact strength; TSS: total sum of square; SSWG: sum of square within group; SSBG: sum of square between group; DFBG: degree of freedom between group; DFWG: degree of freedom within group; F: F test for ANOVA, P-value: probability value; Number of sample $=4$; Number of observations $=20$.

Table 5. ANOVA Test for physical properties of hybrid biocomposites.

\begin{tabular}{cccc}
\hline Source & WU & TSW & DT \\
\hline TSS & 104.804895 & 29.683095 & $72,303.75$ \\
SSWG & 4.8874 & 4.35928 & 6640 \\
SSBG & 99.917495 & 25.323815 & $65,663.75$ \\
DFBG & 3 & 3 & 3 \\
DFWG & 16 & 16 & 16 \\
F-ratio & 109.0341095 & 30.98226007 & 52.74197 \\
$p$-value & 0.00001 & 0.00001 & 0.00001 \\
\hline
\end{tabular}

ANOVA: analysis of variance; WU: water uptake; TSW: thickness swelling; DT: density; TSS: total sum of square; SSWG: sum of square within group; SSBG: sum of square between group; DFBG: degree of freedom between group; DFWG: degree of freedom within group; F: $F$ test for ANOVA, $p$-value: probability value; Number of sample $=4$; Number of observations $=20$. 
Generally, the tricorner approach in the fabrication of the hybrid biocomposites by BR treatment of natural fibers and compatibilization with MA modified PLA, provided a synergistically improved mechanical and physical properties of the hybrid biocomposites, having statistical significance.

\subsection{Thermogravimetric Analysis}

TGA was employed to probe the thermal stability of the hybrid biocomposites by measuring their degree and rate of decomposition or change in mass, as a function of temperature in a controlled atmosphere. The TGA thermograms for the hybrid biocomposites are presented in Figure 3a.

From Figure 3a, clearly, the untreated EFBF-KCF-PLA showed a sharper thermogram around 50-160 ${ }^{\circ} \mathrm{C}$, which can be assigned to the moisture evaporation processes, and the loss of volatile products. The hybrid system EFBF-KCF-PLA, contained a high amount of hemicellulose and impurities, hence, its moisture content should have been higher. The initial and maximum decomposition temperatures (i.e., $T_{\text {onset }}$ and $T_{\max }$ ) of the EFBF-KCF-PLA tended to rise slightly after the fibers were treated with aqueous BR solution i.e., BR(EFBF-KCF)-PLA (Figure 3a). This indicates that the elimination of hemicellulose along with other fiber surface impurities by the BR, improved the thermal resistance of the hybrid biocomposites [43,44].

Synergistically improved thermal stability was provided by BR(EFBF-KCF)-MAPLA, which may have been a result of the strong interface bonds formed by the BR-treated hybrid fiber and MA-modified PLA. The rich-lignin content of KCF could also aid the thermal stability of the hybrid biocomposites. These results correlated with earlier findings on the mechanical and physical properties of the hybrid biocomposites.
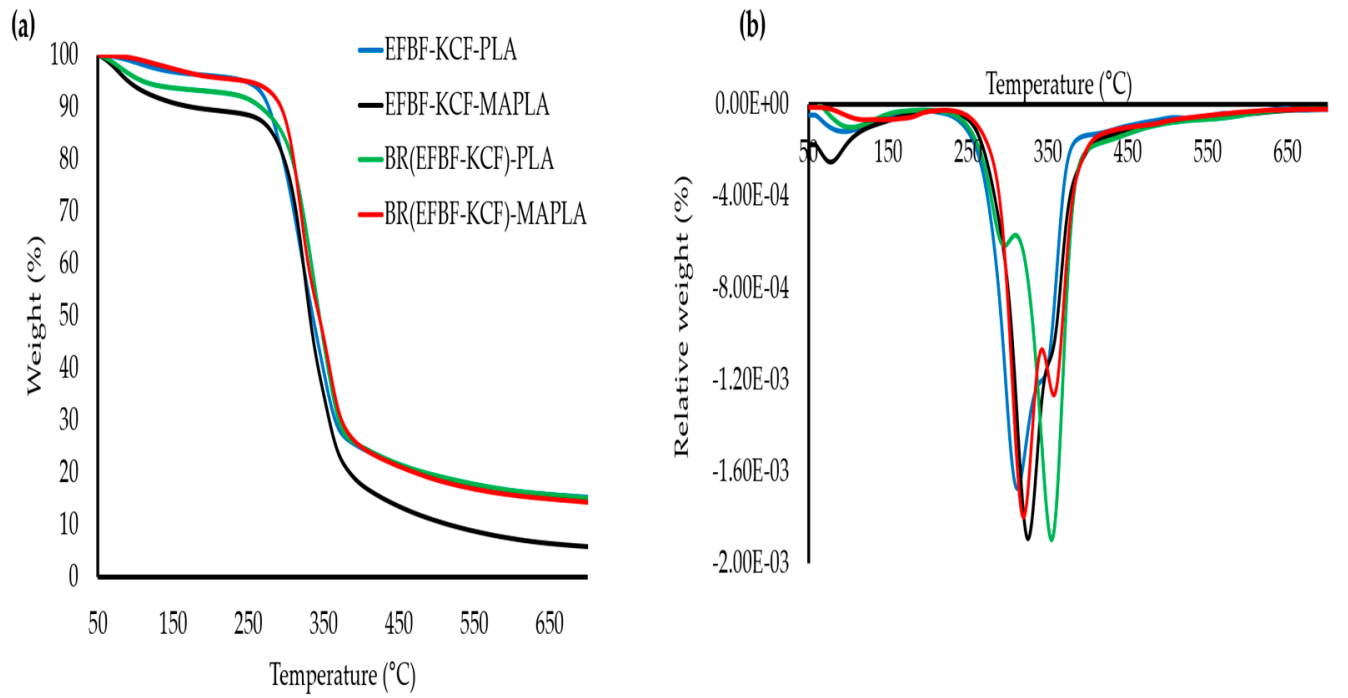

Figure 3. Thermogravimetric analysis (TGA) (a), and DTG (b) thermograms of hybrid biocomposites.

However, the DTG thermograms for the hybrid biocomposites given in Figure $3 b$, shows that, beside the weight losses around $50-160{ }^{\circ} \mathrm{C}$ which can be ascribed to moisture evaporation processes, two additional thermograms also appeared. The first thermogram appeared at around $250-300{ }^{\circ} \mathrm{C}$, and was assigned as hemicellulose and early cellulose decomposition. Hemicellulose degrades at higher rate because it is more thermally unstable than cellulose and lignin [45].

The second thermogram appeared at around $300-450{ }^{\circ} \mathrm{C}$, and was ascribed as late cellulose and early lignin decomposition. Lignin decomposes slowly and covers a wide temperature range, owing to its different oxygen-containing functional groups which possess varying thermal stabilities [46,47]. The residue ash recorded at $700{ }^{\circ} \mathrm{C}$ includes EFBF-KCF-PLA (10.23\%), EFBF-KCF-MAPLA (14.99\%), BR(EFBF-KCF)-PLA (18.06\%), and BR(EFBF-KCF)-MAPLA (17.44\%). Generally, increase in thermal 
degradation temperature and residue char formation was observed due to BR treatment of the natural fibers and MA modification of PLA. This observation agreed with previous literature $[48,49]$.

\subsection{Dynamic Mechanical Analysis (DMA)}

The results on dynamic mechanical properties which depict the temperature dependence on dynamic storage modulus (Figure 4a), loss modulus (Figure 4b) and tan $\delta$ (Figure 4c) for the hybrid biocomposites are presented. From Figure $4 \mathrm{a}$, the storage modulus value at $25^{\circ} \mathrm{C}$ for EFBF-KCF-PLA hybrid system was $1936 \mathrm{MPa}$, which increased upon BR treatment of fibers i.e., BR(EFBF-KCF)-PLA (1952 MPa). Further significant improvement was noted in the hybrid system, involving BR-treated hybrid fiber reinforced MA modified PLA i.e., BR(EFBF-KCF)-MAPLA (2998 MPa). This trend remained similar even at higher temperatures, hence suggesting that BR(EFBF-KCF)-MAPLA has a better storage modulus among the hybrid systems. Previously, addition of MA has been reported to improve the storage modulus of PP-clay hybrid [50]. Also, the storage modulus of all the hybrid systems tended to decrease upon temperature rise, perhaps due to the change in the nature of the materials from plastic to viscous [51-53].
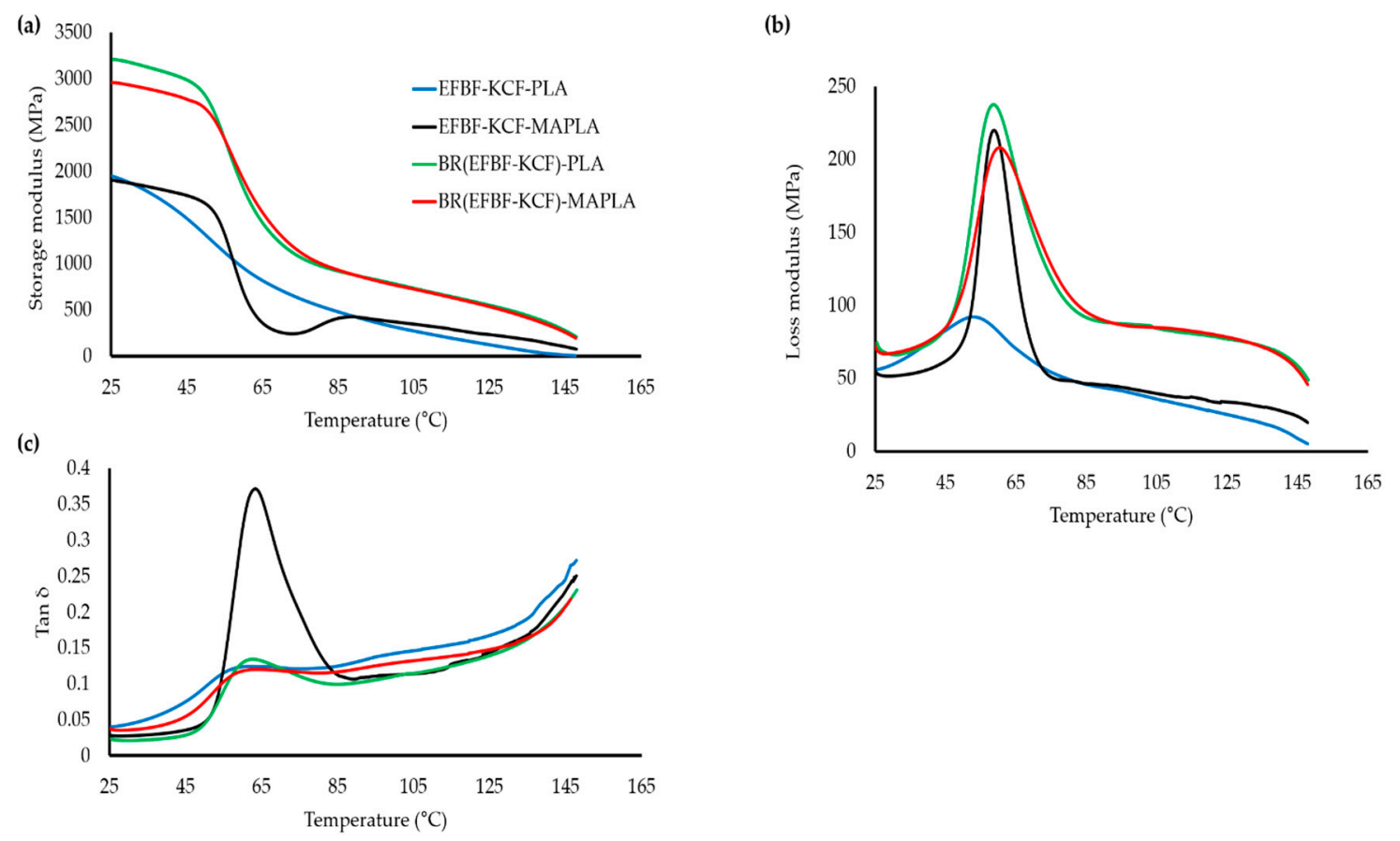

Figure 4. Storage modulus (a); loss modulus (b); and $\tan \delta$ (c) curves of hybrid biocomposites.

The EFBF-KCF-PLA hybrid system showed a minimal value of loss modulus (Figure $4 \mathrm{~b}$ ) at $65^{\circ} \mathrm{C}$. Similar minimal loss modulus values for natural fiber thermoplastic composites were also observed by [54]. However, hybridization of KCF with EFBF, improved the loss modulus at higher temperatures, which could be due to enhanced fiber-polymer interfacial bonding, occurring due to the reinforcing ability of lignin-rich KCF. The $T_{\mathrm{g}}$ values recorded included EFBF-KCF-PLA $\left(52.90^{\circ} \mathrm{C}\right)$, EFBF-KCF-MAPLA $\left(58.86^{\circ} \mathrm{C}\right), \mathrm{BR}(\mathrm{EFBF}-\mathrm{KCF})$-PLA $\left(58.68^{\circ} \mathrm{C}\right)$, and BR(EFBF-KCF)-MAPLA $\left(60.32{ }^{\circ} \mathrm{C}\right)$. Thus, in terms of $T_{\mathrm{g}}, \mathrm{BR}(\mathrm{EFBF}-\mathrm{KCF})$-MAPLA possessed optimal thermal stability, consequent of the synergistic enhancement in the interface adhesion, provided by the BR-treated hybrid fibers and MA-modified PLA. This observation interrelated with earlier statements on the TGA, and the mechanical and physical properties of the hybrid biocomposites.

Figure $4 \mathrm{c}$ shows the $\tan \delta$ peaks of the hybrid biocomposites, which clearly showed that, at $25^{\circ} \mathrm{C}$, the lowest results were attained by BR(EFBF-KCF)-MAPLA compared to BR(EFBF-KCF)-PLA, EFBF-KCF-MAPLA and EFBF-KCF-PLA, respectively. This showed that hybrid systems involving the 
combined methods of BR treatment of fiber and compatibilization with MA-modified PLA provided lowest tendency to extricate energy, which suggests that they have a better thermal stability in relation to those hybrid systems produced using separate modification methods.

\subsection{Morphology of Fractured Surfaces}

The morphologies of the fractured surfaces of the hybrid systems i.e., EFBF-KCF-PLA (Figure 5a), EFBF-KCF-MAPLA (Figure 5b), BR(EFBF-KCF)-PLA (Figure 5c), and BR(EFBF-KCF)-MAPLA (Figure 5d) are shown respectively. The hybrid system i.e., BR(EFBF-KCF)-MAPLA showed rough surfaces with no holes, micro-cracks or gaps (Figure $5 \mathrm{~d}$ ), perhaps due to better interface adhesion provided by the BR-treated hybrid fibers, and compatibilization effect provided by the MA-modified PLA. This finding agreed with earlier results on the DMA, TGA, mechanical and physical properties stated. In the micrograph of BR(EFBF-KCF)-PLA (Figure 5c), few cracks and gaps were seen. Those of EFBF-KCF-MAPLA (Figure 5b) and EFBF-KCF-PLA (Figure 5a) showed holes, micro-cracks and gaps, which may have contributed to their relatively lower material properties (i.e., mechanical, physical, thermal and dynamic mechanical), arising due to weaker interface adhesion from a high content of hemicellulose, and the brittle behavior of the unmodified PLA [55], especially in the hybrid system EFBF-KCF-PLA.
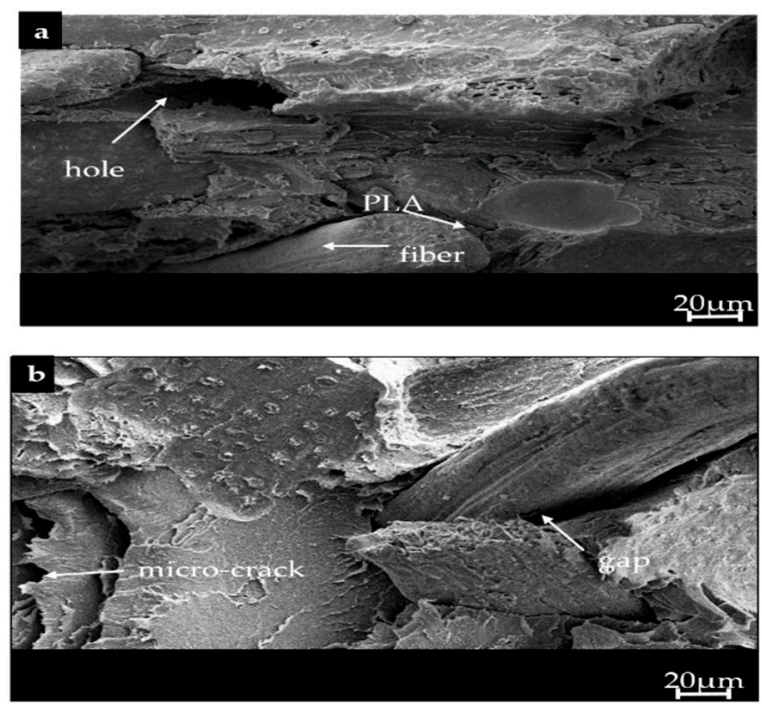
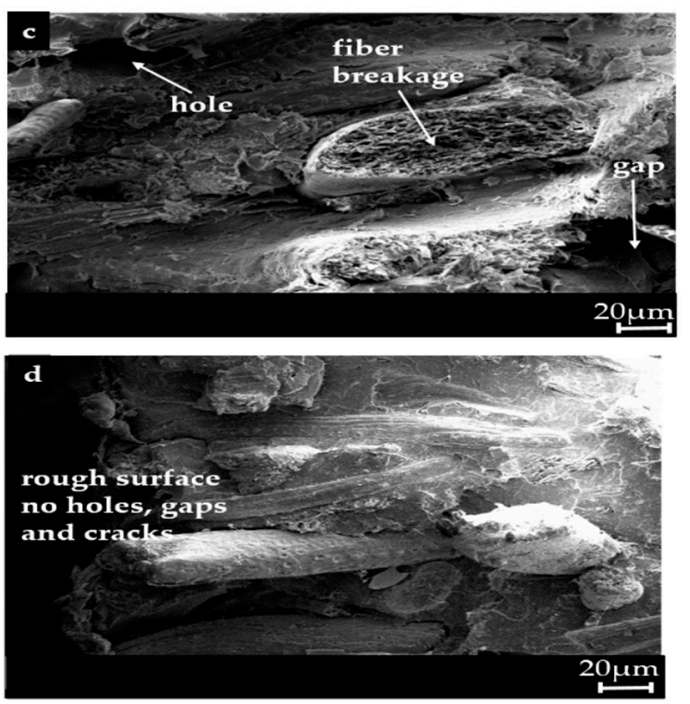

Figure 5. Morphology of fractured surfaces of (a) EFBF-KCF-PLA; (b) BR(EFBF-KCF)-PLA; (c) EFBF-KCF-MAPLA; and (d) BR(EFBF-KCF)-MAPLA.

\section{Conclusions}

This study demonstrated that MA modification of PLA could aid in the synergistic improvement of the mechanical, physical, thermal, dynamic mechanical and morphological properties of hybrid biocomposites fabricated using a combination of BR-treated EFBF and KCF as reinforcements i.e., BR(EFBF-KCF)-MAPLA. This hybrid system, compared to its corresponding systems, was observed to possess relatively better interface adhesion, which consequently enhanced its tensile, flexural, impact, thermal and dynamic mechanical properties. The water uptake and thickness swelling of the BR(EFBF-KCF)-MAPLA hybrid system was less pronounced, and its density was lower compared to its corresponding hybrid systems. However, its recorded density was higher than those of conventional MDF, and similar to the density of HDF. The application of the BR(EFBF-KCF)-MAPLA hybrid biocomposites, compared to its corresponding ones, as alternative fiberboards is potentially promising, as a cleaner and sustainable option to conventional fiberboard usage. 
Acknowledgments: The authors are profoundly grateful for the funding facilities that supported this research, kindly provided by the leadership of polymer research group, Universiti Putra Malaysia (UPM) as well as Tertiary Education Trust Fund (TETFUND), Nigeria. Research facilities were also provided by Universiti Putra Malaysia (UPM).

Author Contributions: Abubakar Umar Birnin-Yauri: designed and performed the experiment, analysed the data and wrote the paper; Nor Azowa Ibrahim: conceived and supervised the experiment, provided reagents, materials and tools; Norhazlin Zainuddin and Khalina Abdan: contributed in supervision of the experiment; Buong Woei Chieng and Yoon Yee Then: critically reviewed the manuscript.

Conflicts of Interest: No conflict of interest is declared by the authors.

\section{References}

1. Clemons, C.M.; Caulfield, D.F. Natural fibers. Funct. Fill. Plast. 2010, 3, 195-206.

2. Jawaid, M.; Abdul-Khalil, H.P.S. Cellulosic/synthetic fibre reinforced polymer hybrid composites: A review. Carbohydr. Polym. 2011, 86, 1-18. [CrossRef]

3. Abdul-Khalil, H.P.S.; Firdaus, M.Y.N.; Jawaid, M.; Anis, M.; Ridzuan, R.; Mohamed, A.R. Development and material properties of new hybrid medium density fibreboard from empty fruit bunch and rubberwood. Mater. Des. 2010, 31, 4229-4236. [CrossRef]

4. Abdul-Khalil, H.P.S.; Jawaid, M.; Hassan, A.; Paridah, M.T.; Zaidon, A. Oil palm biomass fibres and recent advancement in oil palm biomass fibres based hybrid biocomposites. Compos. Appl. 2012, 3, 187-220.

5. Sulaiman, F.; Abdullah, N.; Gerhauser, H.; Shariff, A. An outlook of Malaysian energy, oil palm industry and its utilization of wastes as useful resources. Biomass Bioenergy 2011, 35, 3775-3786. [CrossRef]

6. Pua, F.; Sapuan, S.M.; Zainudin, E.S.; Adib, M.Z. Effect of fibre surface modification on properties of Kenaf/poly(vinyl alcohol ) composite film. J. Biobased Mater. Bioenergy 2013, 95-101. [CrossRef]

7. Ridzwan, M.; Ishak, B. A comparison of mechanical properties between Kenaf core fiber and Kenaf bast fiber reinforced polyester composites. For. Res. 2007, 27, 498-503.

8. El-Shekeil, Y.A.; Sapuan, S.M.; Abdan, K.; Zainudin, E.S. Influence of fiber content on the mechanical and thermal properties of Kenaf fiber reinforced thermoplastic polyurethane composites. Mater. Des. 2012, 40, 299-303. [CrossRef]

9. Abdul-Khalil, H.P.S.; Nurul-Fazita, M.R.; Bhat, A.-H.; Jawaid, M.; Nik-Fuad, N.A. Development and material properties of new hybrid plywood from oil palm biomass. Mater. Des. 2010, 31, 417-424. [CrossRef]

10. Abdul-Khalil, H.P.S.; Suraya, N.L. Anhydride modification of cultivated Kenaf bast fibers: Morphological, spectroscopic and thermal studies. Bio. Res. 2011, 6, 1122-1135.

11. Bergert, D.L. Management strategies of Elaeis guineensis (oil palm) in response to localized markets in south eastern Ghana, west Africa. M.Sc. Thesis, Michigan Technological University, Michigan, MI, USA, 2000.

12. Wahid, M.B.; Nor, S.; Abdullah, A.; Henson, I.E. Oil palm-Achievements and potential. Plant Prod. Sci. 2005, 8, 1-13. [CrossRef]

13. Aji, I.S.; Sapuan, S.M.; Zainudin, E.S.; Abdan, K. Kenaf fibres as reinforcement for polymeric composites: A review. Int. J. Mech. Mater. Eng. 2009, 4, 239-248.

14. Birnin-Yauri, A.U.; Ibrahim, N.A.; Zainuddin, N.; Abdan, K.; Then, Y.Y.; Chieng, B.W. Influence of Kenaf core fiber incorporation on the mechanical performance and dimensional stability of oil palm fiber reinforced poly(lactic acid) hybrid biocomposites. BioResources 2016, 11, 3332-3355. [CrossRef]

15. He, Z.; Zhang, Y.; Wei, W. Formaldehyde and VOC emissions at different manufacturing stages of wood-based panels. Build. Environ. 2012, 47, 197-204. [CrossRef]

16. Kim, S.; Kim, H.J. Comparison of standard methods and gas chromatography method in determination of formaldehyde emission from MDF bonded with formaldehyde-based resins. Bioresour. Technol. 2005, 96, 1457-1464. [CrossRef] [PubMed]

17. Nasir, M.; Gupta, A.; Beg, M.D.H.; Chua, G.K.; Kumar, A. Fabrication of medium density fibreboard from enzyme treated rubber wood (hevea brasiliensis) fibre and modified organosolv lignin. Int. J. Adhes. Adhes. 2013, 44, 99-104. [CrossRef]

18. Chieng, B.W.; Ibrahim, N.A.; Yunus, W.M.; Hussein, M. Poly(lactic acid)/poly(ethylene glycol) polymer nanocomposites: Effects of graphene nanoplatelets. Polymers 2013, 6, 93-104. [CrossRef]

19. Mukherjee, T.; Kao, N. PLA based biopolymer reinforced with natural fibre: A review. J. Polym. Environ. 2011, 19, 714-725. [CrossRef] 
20. Velmurugan, R.; Manikandan, V. Mechanical properties of palmyra/glass fiber hybrid composites. Compos. Part A Appl. Sci. Manuf. 2007, 38, 2216-2226. [CrossRef]

21. Then, Y.Y.; Ibrahim, N.A.; Zainuddin, N.; Ariffin, H.; Yunus, W.M.; Chieng, B.W. The influence of green surface modification of oil palm mesocarp fiber by superheated steam on the mechanical properties and dimensional stability of oil palm mesocarp fiber/poly(butylene succinate) biocomposite. Int. J. Mol. Sci. 2014, 15, 15344-15357. [CrossRef] [PubMed]

22. Asumani, O.M.L.; Reid, R.G.; Paskaramoorthy, R. The effects of alkali-silane treatment on the tensile and flexural properties of short fibre non-woven Kenaf reinforced polypropylene composites. Compos. Part A Appl. Sci. Manuf. 2012, 43, 1431-1440. [CrossRef]

23. Ishak, M.R.; Leman, Z.; Sapuan, S.M.; Salleh, M.Y.; Misri, S. The effect of sea water treatment on the impact and flexural strength of sugar palm fibre reinforced epoxy composites. Int. J. Mech. Mater. Eng. 2009, 4, 316-320.

24. Kaddami, H.; Dufresne, A.; Khelifi, B.; Bendahou, A.; Taourirte, M.; Raihane, M.; Issartel, N.; Sautereau, H.; Gérard, J.F.; Sami, N. Short palm tree fibers-Thermoset matrices composites. Compos. Part A Appl. Sci. Manuf. 2006, 37, 1413-1422. [CrossRef]

25. Donmez-Cavdar, A.; Mengeloğlu, F.; Karakus, K. Effect of boric acid and borax on mechanical, fire and thermal properties of wood flour filled high density polyethylene composites. Measurement 2015, 60, 6-12. [CrossRef]

26. Özalp, M. The effect of borax pentahydrate addition to urea formaldehyde on the mechanical characteristics and free formaldehyde content of medium density fiberboard (MDF). Eur. J. Wood Wood Prod. 2010, 68, 117-119. [CrossRef]

27. Widiarto, S. Effect of borax on mechanical properties and biodegradability of sago starch-poly(vinyl alcohol) blend films. BioResources 2005, 11, 151-157.

28. Birnin-Yauri, A.U.; Ibrahim, N.A.; Zainuddin, N.; Abdan, K.; Then, Y.Y.; Chieng, B.W. Enhancement of the mechanical properties and dimensional stability of oil palm empty fruit bunch-Kenaf core and oil palm mesocarp-Kenaf core hybrid fiber reinforced poly(lactic acid) biocomposites by borax decahydrate modification of fibers. BioResources 2016, 11, 4865-4884. [CrossRef]

29. Saba, N.; Tahir, P.; Jawaid, M. A Review on potentiality of nano filler/natural fiber filled polymer hybrid composites. Polymers 2014, 8, 2247-2273. [CrossRef]

30. Zhu, J.; Njuguna, J.; Abhyankar, H.; Zhu, H.; Perreux, D.; Thiebaud, F.; Chapelle, D.; Pizzi, A.; Sauget, A.; de Larminat, A.; et al. Effect of fibre configurations on mechanical properties of flax/tannin composites. Ind. Crops Prod. 2013, 50, 68-76. [CrossRef]

31. Silverajah, V.S.G.; Ibrahim, N.A.; Zainuddin, N.; Yunus, W.M.Z.W.; Hassan, H.A. Mechanical, thermal and morphological properties of poly(lactic acid)/epoxidized palm olein blend. Molecules 2012, 17, 11729-11747. [CrossRef] [PubMed]

32. Ma, P.; Jiang, L.; Ye, T.; Dong, W.; Chen, M. Melt free-radical grafting of maleic anhydride onto biodegradable poly(lactic acid) by using styrene as a comonomer. Polymers 2014, 6, 1528-1543. [CrossRef]

33. Canetti, M.; Bertini, F.; De Chirico, A.; Audisio, G. Thermal degradation behaviour of isotactic polypropylene blended with lignin. Polym. Degrad. Stab. 2006, 91, 494-498. [CrossRef]

34. Muenprasat, D.; Suttireungwong, S.; Tongpin, C. Functionalization of poly(lactic acid) with maleic anhydride for biomedical application. J. Met. Mater. Min. 2010, 20, 189-192.

35. Palacio, J.; Orozco, V.H.; López, B.L. Effect of the molecular weight on the physicochemical properties of poly(lactic acid) nanoparticles and on the amount of ovalbumin adsorption. J. Braz. Chem. Soc. 2011, 22, 2304-2311. [CrossRef]

36. Peng, Y.; Wu, P.; Yang, Y. Two-dimensional infrared correlation spectroscopy as a probe of sequential events in the diffusion process of water in poly caprolactone. J. Chem. Phys. 2003, 119, 8075-8079. [CrossRef]

37. Orozco, V.H.; Brostow, W.; Chonkaew, W.; Lo, B.L. Preparation and characterization of poly(lactic acid)g-maleic anhydride starch blends. Macromol. Sympos. 2009, 4, 69-80. [CrossRef]

38. Tsou, C.; Hung, W.; Wu, C.; Chen, J.; Chiu, S.; Tsou, C.; Yao, W.; Lin, S.; Chu, C.; Hu, C.; et al. New composition of maleic-anhydride-grafted poly(lactic acid)/rice husk with methylenediphenyl diisocyanate. Mater. Sci. 2014, 20. [CrossRef]

39. Shen, Y.; Qi, R.; Liu, Q.; Wang, Y.; Mao, Y.; Yu, J. Grafting of maleic anhydride onto polyethylene through a green chemistry approach. J. Appl. Polym. Sci. 2008, 110, 2261-2266. [CrossRef] 
40. Lionetto, F.; Del Sole, R.; Cannoletta, D.; Vasapollo, G.; Maffezzoli, A. Monitoring wood degradation during weathering by cellulose crystallinity. Materials 2012, 5, 1910-1922. [CrossRef]

41. Then, Y.Y.; Ibrahim, N.A.; Zainuddin, N.; Chieng, B.W.; Ariffin, H. Influence of alkaline-peroxide treatment of fiber on the mechanical properties of oil palm mesocarp fiber/poly(butylene succinate) biocomposite. BioResources 2015, 10, 1730-1746. [CrossRef]

42. Rivela, B.; Moreira, M.T.; Feijoo, G. Life cycle inventory of medium density fibreboard. Int. J. Life Cycle Assess. 2007, 12, 143-150. [CrossRef]

43. Wang, S.; Lee, S.; Wang, S. Biodegradable polymers/bamboo fiber biocomposite with bio-based coupling agent biodegradable polymers/bamboo fiber biocomposite with bio-based coupling agent. Compos. Part $A$ 2016, 37, 80-91.

44. Abdelwahab, M.A.; Flynn, A.; Chiou, B.S.; Imam, S.; Orts, W.; Chiellini, E. Thermal, mechanical and morphological characterization of plasticized PLA-PHB blends. Polym. Degrad. Stab. 2012, 97, 1822-1828. [CrossRef]

45. Peng, F.; Bian, J.; Peng, P.; Guan, Y.; Xu, F.; Sun, R.C. Fractional separation and structural features of hemicelluloses from sweet sorghum leaves. BioResources 2012, 7, 4744-4759. [CrossRef]

46. Heikkinen, J.M.; Hordijk, J.C.; De Jong, W.; Spliethoff, H. Thermogravimetry as a tool to classify waste components to be used for energy generation. J. Anal. Appl. Pyrolysis. 2004, 71, 883-900. [CrossRef]

47. Then, Y.Y.; Ibrahim, N.A.; Zainuddin, N.; Ariffin, H.; Yunus, W.M.; Chieng, B.W. Surface modifications of oil palm mesocarp fiber by superheated steam, alkali, and superheated steam-alkali for biocomposite applications. BioResources 2014, 9, 7467-7483. [CrossRef]

48. Siyamak, S.; Ibrahim, N.A.; Abdolmohammadi, S.; Yunus, W.M.Z.B.W.; Rahman, M.Z.A.B. Enhancement of mechanical and thermal properties of oil palm empty fruit bunch fiber poly(butylene adipate-co-terephtalate) biocomposites by matrix esterification using succinic anhydride. Molecules 2012, 17, 1969-1991. [CrossRef] [PubMed]

49. Nordin, N.I.A.A.; Ariffin, H.; Andou, Y.; Hassan, M.A.; Shirai, Y.; Nishida, H.; Yunus, W.M.Z.W.; Karuppuchamy, S.; Ibrahim, N.A. Modification of oil palm mesocarp fiber characteristics using superheated steam treatment. Molecules 2013, 18, 9132-9146. [CrossRef] [PubMed]

50. Hasegawa, N.; Kawasumi, M.; Kato, M.; Ukudi, A.; Okada, A. Preparation and mechanical properties of polypropylene-clay hybrids using a maleic-anhydride grafted polypropylene oligomer. J. Appl. Polym. Sci. 1998, 67, 87-92. [CrossRef]

51. Wang, X.; Sun, H.; Bai, H.; Zhang, L. Thermal, mechanical, and degradation properties of nanocomposites prepared using lignin-cellulose nanofibers and poly(lactic acid). BioResources 2014, 9, 3211-3224. [CrossRef]

52. Nayak, S.K.; Mohanty, S.; Samal, S.K. Influence of short bamboo/glass fiber on the thermal, dynamic mechanical and rheological properties of polypropylene hybrid composites. Mater. Sci. Eng. A 2009, 523, 32-38. [CrossRef]

53. Yu, T.; Ren, J.; Li, S.; Yuan, H.; Li, Y. Effect of fiber surface-treatments on the properties of poly(lactic acid)/ramie composites. Compos. Part A Appl. Sci. Manuf. 2010, 41, 499-505. [CrossRef]

54. Sreenivasan, V.S.; Rajini, N.; Alavudeen, A.; Arumugaprabu, V. Dynamic mechanical and thermo-gravimetric analysis of Sansevieria cylindrica/polyester composite: Effect of fiber length, fiber loading and chemical treatment. Compos. Part B Eng. 2015, 69, 76-86. [CrossRef]

55. Alam, J.; Alam, M.; Raja, M.; Abduljaleel, Z.; Dass, L. MWCNTs-reinforced epoxidized linseed oil plasticized polylactic acid nanocomposite and its electroactive shape memory behaviour. Int. J. Mol. Sci. 2014, 15, 19924-19937. [CrossRef] [PubMed]

(C) 2017 by the authors. Licensee MDPI, Basel, Switzerland. This article is an open access article distributed under the terms and conditions of the Creative Commons Attribution (CC BY) license (http:/ / creativecommons.org/licenses/by/4.0/). 